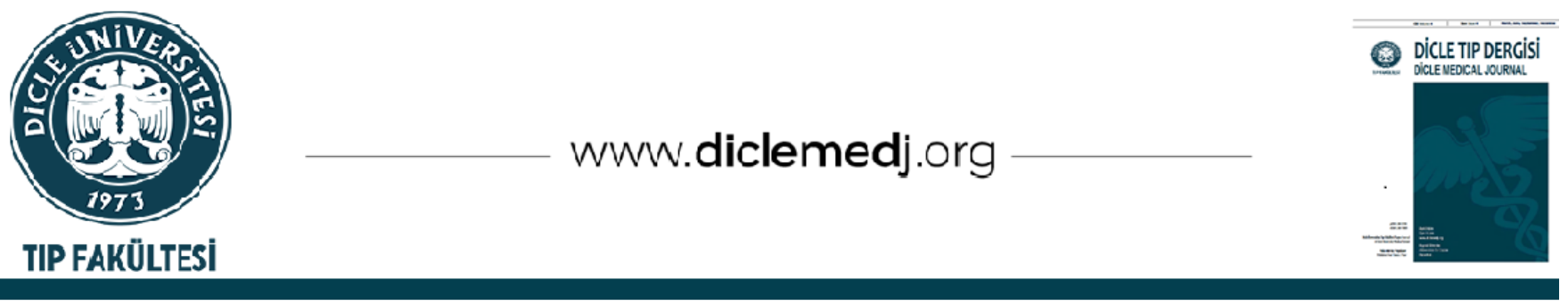

Özgün Araştırma / Original Article

\title{
Uykuda Solunum Bozukluğu Şikayeti Olan 60-75 Yaş Arasındaki Yaşlı Bireylerde Aşırı Kilo / Obezite ve Obstrüktif Uyku Apne Sendromu Arasındaki Epidemiyolojik İlişki
}

\author{
Murat Kayabekir ${ }^{D_{1}}$ \\ 1 Atatürk Üniversitesi Tıp Fakültesi, Fizyoloji Anabilim Dalı, Erzurum, Türkiye
}

Geliş: 12.09.2020; Revizyon: 06.03.2021; Kabul Tarihi: 18.03.2021

Öz

Amaç: Bu çalışmanın amacı uykuda solunum bozukluğu şikayeti olan 60-75 yaş arasındaki yaşlı bireylerde aşırı kilo/obezite ile obstrüktif uyku apne sendromu (OUAS) ilişkisinin değerlendirilmesi ve eșlik eden risk faktörlerinin araştırılmasıdır.

Yöntemler: Uyku ve Elektrofizyoloji Laboratuvarı' na uykuda solunum bozukluğu şikayeti ile başvuran 300 hasta [E/K, 152/148; yaş ortalaması ( \pm SD), 65,2 $\pm 4,0$ yıl]' ya ait 5 yıllık polisomnografi (PSG) kayıtları ve diğer tanısal verileri incelenmiştir.

Bulgular: Uykuda solunum bozukluğu şikayetleri olan 60 yaş üstündeki bireylerin sadece 27' si (\%9) OUAS tanısı almamıştır. Geri kalan 273 yaşlı hastanın 81' i (\%27) hafif, 56' sı (\%18,7) orta, 136 (\%45,3)' sı ise ağır derece OUAS tanısı almıştır. Ayrıca 22' si (\%7,3) normal vücut kitle indeksine sahip iken; 64' ü $(\% 21,3)$ aşırı kilolu, 161' i $(\% 53,7)$ obez, 53' ü $(\% 17,7)$ morbid obez olarak sınıflandırılmıștır. Toplam morbidite oranlarına bakıldığında $\% 51,3$ hipertansiyon, $\% 26,3$ diyabet olduğu anlaşılmıştır.

Sonuç: Bu kesitsel çalışma uykuda solunum bozukluğu şikayeti olan 60 yaş üstü bireylerde; aşırı kilo/obezite/ OUAS sıklı̆̆ının belirgin olduğunu, aynı yaş grubundaki normal populasyon ile karşılaştırma yapılamamış olsa da, hipertansiyon, diyabet gibi kardiyovasküler risk faktörlerinin bu vakalara eşlik ettiğini göstermiştir.

Anahtar kelimeler: Yaşli; kilolu; obezite; uyku apnesi, tıkayıcı

DOI: $10.5798 /$ dicletip. 944376

Yazıșma Adresi / Correspondence: Murat Kayabekir, Atatürk Üniversitesi Tıp Fakültesi, Fizyoloji Anabilim Dalı, Erzurum, Türkiye email: kayabekirmurat@gmail.com 


\title{
The Epidemiological Relationship between Overweight / Obesity and Obstructive Sleep Apnea Syndrome in Elderly People between 60-75 Years of Age with Complaints of Sleep Breathing Disorders
}

\begin{abstract}
Objective: The aim of this study is to evaluate the relationship between overweight/obesity and obstructive sleep apnea syndrome (OSAS) in elderly people between 60-75 years of age who have complaints of sleep-related breathing disorders (SBD) and to investigate accompanying risk factors.
\end{abstract}

Methods: Five year-long polysomnography (PSG) recordings and other diagnostic data of 300 patients (M/F, 152/148; mean age ( \pm SD), $65.2 \pm 4.0$ years) admitting to the Sleep and Electrophysiology Laboratories with the complaint of SBD were analyzed.

Findings: Of the patients who were above 60 years of age and who had SBD, only 27 individuals (9\%) were not diagnosed with OSAS. Of the remaining 273 patients, 81 (27\%) were diagnosed with mild, $56(18.7 \%)$ with moderate and $136(45.3)$ with severe OSAS. While 22 (7.3\%) patients had normal body mass index; 64 (21.3\%) were classified as overweight, 161 $(53.7 \%)$ as obese and $53(17.7 \%)$ as morbid obese. When total morbidity rates were evaluated, $51.3 \%$ were found to have hypertension, and $26.3 \%$ had diabetes.

Result: In this sectional study, among individuals above 60 years of age with complaints of SBD; the incidence of overweight/obesity/OSAS was significant, despite the fact that no comparison could be made with the normal population at the same age, we could demonstrate that cardiovascular risk factors like hypertension and diabetes frequently accompanied these cases.

Keywords: Elderly; overweight; obesity; sleep apnea, obstructive.

\section{GíRiş}

Yaşlanma yaşayan her organizmada gerçekleşen, tüm işlevlerde azalmaya neden olan evrensel bir süreçtir. Diğer bir deyişle, molekül, hücre, doku, organ ve sistemler düzeyinde süreç içerisinde ortaya çıkan, dönüşü olmayan yapısal ve işlevsel değişikliklerin tamamıdır ${ }^{1}$. Dünya Sağlık Örgütü (DSÖ), yaşlıları kronolojik olarak üçe ayırmıştır: (i) orta yaşlılar (45-59 yaş), (ii) yaşlılar (60-74 yaş), (iii) ihtiyarlar (75 yaş ve üzeri) ${ }^{2}$. Birleșmiş Milletler 60 ve üstü yaştaki bireyleri yaşlı olarak kabul etmektedir. Birçok gelişmiş ülke 65 yaşı özellikle sosyal güvenlik sisteminden yararlanmak için yaşlılığın başlangıcı açısından referans kabul etmektedir ${ }^{3,4}$.

Kalıtım, çevre, bireylerin fizyolojik ve davranışsal özelliklerinin belirleyici olduğu obezite, tüm dünyada sigaradan sonra önlenebilir ikinci ölüm nedeni olarak kabul edilmektedir 4 . Obezite artan morbidite ve mortaliteyi öngörür; başta tip 2 diyabet ve prediyabet olmak üzere kalp-damar hastalıkları, hipertansiyon, hiperlipidemi, serebrovasküler hastalık, çeşitli kanserler, OUAS, non-alkolik karaciğer yağlanması, gastroözofageyal reflü, safra yolları hastalığı, polikistik over sendromu, infertilite, osteoartroz ve depresyon gibi birçok sağlık sorununa neden olarak sağlık harcamalarını arttırmaktadır ${ }^{5}$. Uykuda solunum bozuklukları içinde en sık gözüken OUAS gece boyunca, aralıklarla, tekrar eden, en az 10 saniye veya daha fazla süren solunum durmaları ve azalmaları ile giden, uyku kalitesini bozan tüm vücut organ ve sistemlerini etkileyen klinik bir durumdur ${ }^{5-7}$. Horlama, gündüz uykululuk hali, kilo verememe, gece boğulma hissi, nokturnal aritmiler, noktüri, seksüel impotans, depresyon, unutkanlık, öğrenme problemleri, sabah baş ağrısı, sabah ağız kuruluğu, bruksizm, reflü, uykusuzluk, uykuda anormal motor aktivite, tüm bu semptomlar OUAS' 1 akla getirmektedir6- 
8. Yaşlı yetişkinlerin yarısından fazlası uyku güçlügü bildirmektedir. Geriatrik popülasyondaki uyku şikayetleri; genel sağlık şikayetleri, depresyon ve mortalite ile ilişkilidir. Yaşlılarda uyku şikayetleri çok yaygın olduğundan, klinisyenler bazen bunları dikkate almamaktadır ${ }^{9-13}$. Ancak bu șikayetler çoğunlukla tedavi edilebilir olan uykuda solunum bozukluğundan kaynaklanmaktadır ${ }^{14-}$ 16.

Dünya ve Türkiye nüfusunun hızlıca yaşlanması nedeni ile 60 yaş üzeri yaşlı bireylerin fiziksel ve sosyal sağlıkları önem arz etmektedir. Özellikle ülkemizde yaşlı popülasyona ait aşırı kilo/obezite ve OUAS epidemiyolojisine yönelik literatürde sınırlı sayıda çalışma mevcuttur. Bu çalışmanın amacl, uykuda solunum bozukluğu şikayeti olan yaşlı popülasyonda aşırı kilo/obezite ile OUAS ilişkisinin değerlendirilmesi ve eşlik eden risk faktörlerinin araştırılmasıdır.

\section{YÖNTEMLER}

Erzurum Bölge Eğitim ve Araştırma Hastanesi, Uyku Bozuklukları Merkezi, Elektrofizyoloji Laboratuvarı' na 2013-2017 yılları arasında (5 yil) horlama, gündüz uykululuk hali, gece boğulma hissi ile uyanma, uykusuzluk gibi uykuda solunum bozuklukları şikayetleri ile başvurmuş toplam 300 gönüllü hasta $[\mathrm{E} / \mathrm{K}$, 152/148; yaş, 65,2 $\pm 4,0$ yll; ağırlık, 90,9 $\pm 17,1$ kg; boy, $163,0 \pm 9,4$; boyun, 39,2 $\pm 3,5$ ortalamaları $( \pm S D)]$. Helsinki bildirgesine göre çalışmaya dahil edilmiş olup katılımcılardan bilgilendirilmiş olur alınmıştır. Atatürk Üniversitesi Tıp Fakültesi yerel etik kurulu 0772 / 26.06.2020 numarasıyla bu çalışmayı onaylamıștır. Uyku kalitesi ve uykuda solunum bozuklukları tanısı için laboratuvarda yapılan PSG kayıtları; retrospektif olarak incelenmiștir. Bir gecelik uyku testinde Apne Hipopne İndeksi (AHi) (uykuda 1 saat boyunca solunumun 10 saniye ve üzerinde durması veya azalmasının sayısı) sonuçlarına göre uykuda solunum bozuklukları "ağır, orta ve hafif" derece OUAS olarak sınıflandırılmıștır (Tablo 2). Așırı kilo ve obezite derecelendirmesi vücut kitle indeksi (VKI)' ne dayanarak 'VKİ= Ağırlı (kg)/Boy (m2)" formülü ile değerlendirilmiștir-.

\section{İstatistiksel Analiz}

Verilerin analizi IBM SPSS 25.0 istatistik paket programı kullanılarak yapıldı. Çalışma verileri değerlendirilirken tanımlayıcı istatistiksel metotların (frekans, yüzde, ortalama, standart sapma, medyan, min-max) yanı sıra niteliksel verilerin karșılaștırılmasında Ki-Kare (囵) testi kullanıldı. Verilerin normal dağılıma uygunluğu Kolmogorov-Smirnow ve Shapiro-Wilk, normal dağılım gösteren verilerin gruplar arası karşılaştırmalarında One Way Anova, değişkenler arasındaki korelasyonlar Pearson korelasyon testleri ile değerlendirildi. İhtimali (P) 团=0,05'ten küçük olan değerler önemli ve gruplar arasında fark vardır şeklinde kabul edildi.

\section{BULGULAR}

İncelenen hastalardan sadece 27' si (\%9) OUAS tanısı almamıştır. Geri kalan 273 yaşlı hastanın $81^{\prime}$ i (\%27) hafif derece OUAS, 56' si $(\% 18,7)$ orta derece OUAS, $136(\% 45,3)$ hasta ise ağır derece OUAS tanısı almıştır. Uykuda solunum bozukluğu şikayetleri olan 60 yaş üstündeki bireylerin sadece 22 ' si $(\% 7,3)$ normal VKI' ne sahip iken; 64' ü $(\% 21,3)$ aşırı kilolu, 161' i $(\% 53,7)$ obez, 53' ü $(\% 17,7)$ morbid obez olarak sinıflandırılmıştır. Uykuda solunum bozukluğu şikayetleri olan 60 yaş üstü yaşlı hasta grubunun morbidite oranlarına bakıldığında $\% 51,3$ hipertansiyon, $\% 26,3$ diyabet mevcuttu. Așırı kilolulardan \%33,9' u orta derece OUAS, obezlerden \%59, 6' sı ağır derece OUAS, morbid obezlerden \%26,5' u ağır derece OUAS idi $(\mathrm{p}<0,005)$. Ağır derece OUAS olan 60 yaş üstü bireylerin \%47,8' i kadın, \%52,2' si erkekti. İstatistiksel olarak anlamlı olmamakla beraber ağır derece OUAS tanısı konan yaşlı bireylerin 75' i hipertansif, 42' si diyabetik, 28' i solunumsal, 85' i kardiyovasküler, 51' i 
endokrin, 1'i nörolojik, 1'i de psikiyatrik hastalık tanısı almıştı (sırasıyla, $p=0,226 ; 0,303$; 0677; 0,416; 0,282; 0,155; 0,191). Hastalar OUAS derecelerine göre karşılaştırılmış yaş ve boyları arasında istatistiksel olarak anlamlı bir fark bulunmamıștır (sırasıyla, p: 0,258; 0,747). Ağır derece OUAS' 1 olan hastaların VKİ' si, hafif ve orta derece OUAS' 1 olan ve OUAS saptanmayan hastalara göre istatistiksel olarak anlamlı derecede yüksek bulundu $(p=0,000)$. Ağır derece OUAS' lı yaşlıların boyun çevresi; hafif derece OUAS'ı olan ve OUAS saptanmayan hastalara göre istatistiksel olarak anlamlı yüksek bulunmuştur $(\mathrm{p}<0,05)$ (Tablo I). Uykuda solunum bozuklukları şikayeti olan 60 yaş üstü yaşlı bireylerin VKİ ve AHİ değerleri arasında $r$ $=0,413$ düzeyinde, pozitif yönde ilişki olduğu ve bu ilişkinin istatistiksel olarak anlamlı olduğu bulunmuştur $(\mathrm{p}<0,05)$ (Tablo II). VKİ ve AHİ arasındaki korelasyon grafiği "VKİ=30,67+0,11xAHİ" formülüne uygun olarak Şekil 1' de gösterilmiştir.

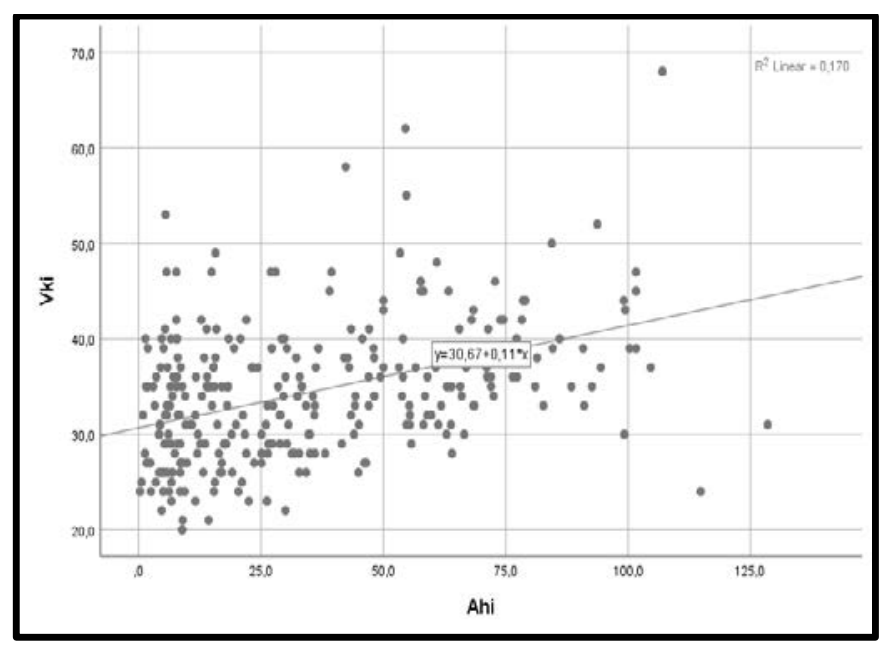

Şekil 1: Uykuda solunum bozukluğu şikayetleri olan 6075 yaş arasındaki yaşlı bireylerin vücut kitle indeksi ve Apne Hipopne İndeksi arasındaki korelasyon grafiği; "VKİ=30,67+0,11xAHİ" doğrusal bağıntı formülü ile ifade edilmiştir.
Tablo I: Uykuda solunum bozukluğu şikayetleri olan 6075 yaş arasındaki yaşlı bireylerin obstruktif uyku apne sendromu derecelerine göre gruplar arası karşılaştırmaları (Mean \pm SD)

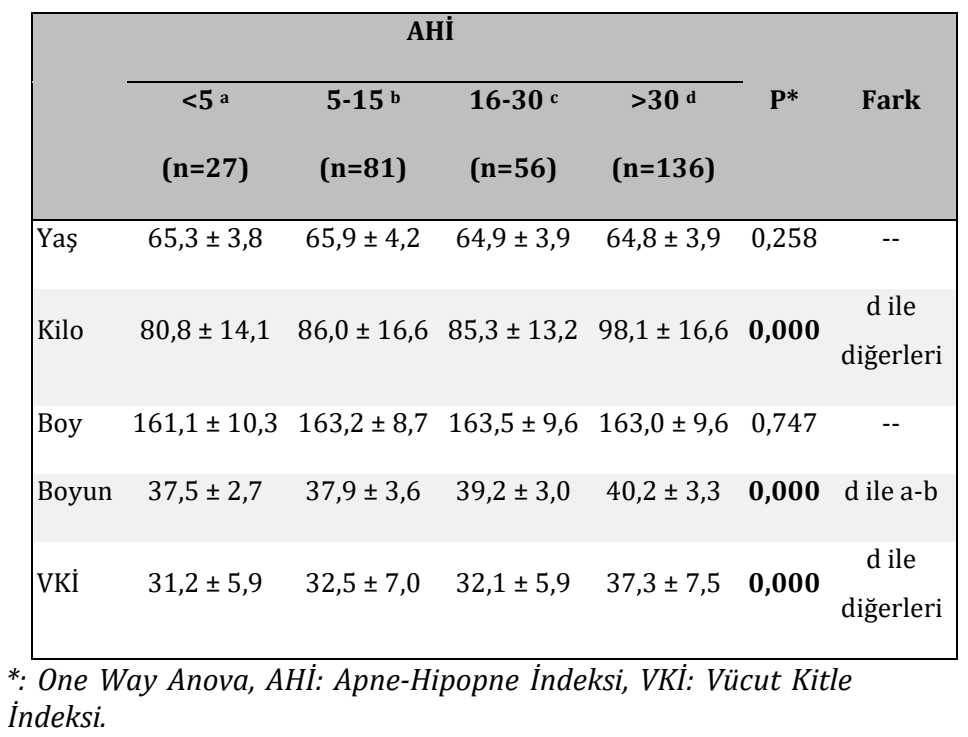

Tablo II: Uykuda Solunum Bozukluğu Şikayetleri olan 6075 yaş arasındaki yaşlı bireylerin VKİ ve AHİ arasındaki ilişki

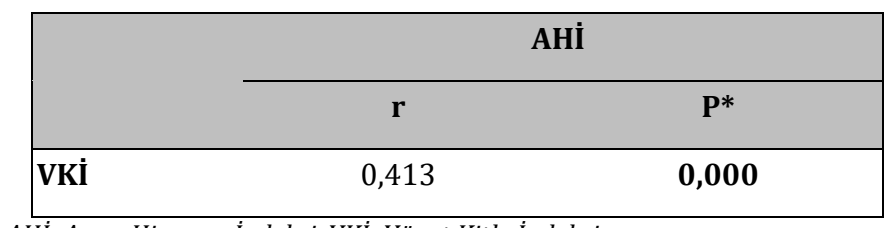

AHİ: Apne-Hipopne İndeksi, VKí: Vücut Kitle Indeksi.

\section{TARTIŞMA}

$\mathrm{Bu}$ çalışma uykuda solunum bozukluğu şikayeti olan 60-75 yaş arasındaki yaşlı bireylerde aşırı kilo / obezite ve OUAS arasındaki epidemiyolojik ilişkiyi anlamaya çalıșmıştır. Çalışmaya katılan yaşlı bireylerden \%21,3' ü aşırı kilolu, \%53,7' si obez, \%17,7 morbid obez, \%45,3' ü ağır derece OUAS idi. Așırı kilolulardan $\% 33,9^{\prime}$ u orta derece OUAS, obezlerden \%59, 6' sı ağır derece OUAS, morbid obezlerden \%26,5' $\mathrm{u}$ ağır derece OUAS idi $(\mathrm{p}<0,005)$. Literatürde yaşlı kişilerde OUAS sıklığına odaklanan veriler yetersizdir. Özellikle, genç OUAS popülasyonlarında ölüm riski artarken, yaşlılarda böyle bir ilişki kurulamamıştır ${ }^{15,16}$. Çalışmamız, yaşlı bireyler için OUAS bağlantılı bir mortalite oranı öngörmemektedir; fakat 5 
yıllık izlemde uykuda solunum şikayetleri ile uyku laboratuvarında PSG yapılmasına karar verilmiș 60 yaș üstündeki bireylerde $\% 91$ OUAS (hafif, orta, ağır) kesitsel prevalans oranı sunmaktadır.

İleri yaşlarda (65 yaş ve üstü), OUAS prevalansının yükseldiği düşünülmüştür ${ }^{17}$. Ancak yaş ile OUAS prevalansı arasındaki ilişki, sanıldığı kadar basit değildir. Apne-Hipopne İndeksi' ne göre yapılan karşılaştırmalarda, yaşlılarda daha sık bozukluk saptanmakta; ancak bunun gündüz uykululuk sonucu gelişen morbidite ve mortalite ile ilișkisi net olarak bilinmemektedir. Huzurevinde 65 yaş üstü yaşlılarda yapılan bir araştırmada, OUAS prevalansı \%62 olarak bildirilmiștir ${ }^{18}$. Ancak, yaş faktörünün tek başına OUAS riskini artırıp artırmadığı tam olarak açıklığa kavuşmamıştır. Hastalığın yaşla birlikte artışı, 65' in üstündeki yaşlarda, 65' in altındakiler kadar net olmadığ anlaşılmıştır ${ }^{19}$. Bu durum, OUAS hastalarının OUAS bulunmayan kişilere oranla ölüm riskinin yüksek olması veya hastalığın yaşla birlikte azalması ile açıklanabilir. Ancak OUAS' ın ölüme neden olduğu veya yaşla azaldığı ile ilgili kesin bir ispat yoktur ${ }^{20}$. Başta hipotiroidi, metabolik bozukluklar, diyabet ve hipertansiyon gibi komorbiditelerin OUAS'a sık eşlik ettiği bilinse de, bu birlikteliğin yaş ile ilişkisine yönelik sonuçlar çelişkilidir ${ }^{21}$. Yapılan bu makale çalışmasındaki morbidite oranlarına bakıldığında \%51,3 hipertansiyon, \%26,3 diyabet olduğu; ağır derece OUAS' lı yaşlı bireylerde sadece kardiyovasküler morbidite oranının ise \%62,5 olduğu anlaşılmıştır. Obez hasta grubunun \%59,6'sında ağır derece OUAS görülmesi, ileri yaş grubunda aşırı kilo/obezite ile OUAS arasında bir ilișki olabileceğini göstermektedir. Bu çalışma 60 yaş üstünde özellikle OUAS ve obezite sıklığının belirgin olduğunu vurgulamıştır.

Amerika Birleşik Devletleri'nde, üç yetişkinden ikisi ideal vücut ağırlığından daha ağırdır. En son Ulusal Sağllk ve Beslenme İnceleme Anketi' ne (National Health and Nutrition Examination Survey (NHANES)) göre, ABD yetişkinlerinin $\% 66,2^{\prime}$ si aşırı kilolu, \%32,9' u obez ve \%4,8' i morbid obez olduğu rapor edilmiștir. Obezite, OUAS dahil birçok komplikasyon ile ilişkilidir ${ }^{22}$. OUAS ile ateroskleroz için pek çok risk faktörü ortaktır; obezite, yaş, erkek cinsiyet, metabolik sendrom, sigara, high sensivity C- Reactive Protein (hsCRP) seviyelerinde artış ve insulin direnci her iki duruma özgü parametrelerdir ${ }^{23}$. Ülkemizde obezite prevalansı, 20'li yaşlardan itibaren artarak kadınlarda 45-74 yaş grubunda $\% 50$ ' yi ve erkeklerde 45-64 yaş grubunda \%30' u aşmakta, ileri yaşlarda ise azalma eğilimi göstermektedir ${ }^{24}$. Bu kesitsel çalışma, genel populasyonu yansitmamakla beraber; ileri yaşlarda uykuda solunum bozukluğu şikayetleri olan bireylerde obezite sıklığının belirgin olduğunu ortaya koymuştur.

Beş yllık retrospektif kesitsel bir analizi ortaya koyan bu çalışmanın zayıf tarafı; güçlü epidemiyolojik sonuçlar için daha fazla sayıda katılımcıya ihtiyaç duymasıdır. Dünyada ve Türkiye' de çok önemli bir popülasyon haline gelmesi beklenen 60 yaş üstü bireyler için en azından ülkemizdeki uyku laboratuvarı verileri uyku dernekleri aracılığı ile toplanabilir; böylece yaşlı bireylerin obezite, OUAS ve sistemik komplikasyonlarının önlenebilmesi için çok önemli bir adım atılmış olur.

Bu kesitsel çalışma uykuda solunum bozukluğu şikayeti olan 60 yaş üstü bireylerde; aşırı kilo/obezite/ OUAS sıklı̆̆ının belirgin olduğunu, aynı yaş grubundaki normal populasyon ile karşılaştırma yapılamamış olsada, hipertansiyon, diyabet gibi kardiyovasküler risk faktörlerinin bu vakalara eşlik ettiğini göstermiştir.

Etik Kurul Kararı: Helsinki bildirgesine göre çalışmaya dahil edilmiş olup katılımcılardan bilgilendirilmiş olur alınmıştır. Atatürk Üniversitesi Tıp Fakültesi yerel etik kurulu 0772 / 26.06.2020 numarasıyla bu çalışmayı onaylamıștır. 
Çıkar Çatışması Beyanı: Yazarlar çıkar çatışması olmadığını bildirmişlerdir.

Finansal Destek: Bu çalışma her hangi bir fon tarafından desteklenmemiştir.

Declaration of Conflicting Interests: The authors declare that they have no conflict of interest.

Financial Disclosure: No financial support was received.

\section{KAYNAKLAR}

1. Dyussenbayev A. The periods of human life. Glob J Hum Soc Sci. 2017; 17: 32-6. 10.

2. McHugh D, Gil J. Senescence and aging: Causes, consequences, and therapeutic avenues. J Cell Biol. 2018; 217: 65-77.

3. World Health Organization. WHO Fact sheet on overweight and obesity. Updated October 2017. http://www.who.int/mediacentre/factsheets/fs 311/en/. Erişim tarihi: 01. Nisan. 2020.

4. World Health Organization. Obesity Preventing and Managing the Global Epidemic: Report of a WHO Consultation on Obesity. WHO/NUT/NCD/1998.https://www.who.int/nutri tion/publications/obesity/WHO_TRS_894/en/ Erişim tarihi: 01. Mart. 2021.

5. Kayabekir M. Updates in Sleep Neurology and Obstructive Sleep Apnea. Diagnosis, First edn. London: Fabian HR, 2020: 1-13.

6. Kayabekir M. Updates in Sleep Neurology and Obstructive Sleep Apnea. Sleep Physiology and Polysomnogram, Physiopathology and Symptomatology in Sleep Medicine, First edn. London: Fabian HR, 2019: 5-12.

7. Foley DJ, Monjan AA, Brown SL, Simonsick EM, Wallace RB, Blazer DG. Sleep complaints among elderly persons: an epidemiologic study of three communities. Sleep. 1995; 18: 425-32.

8. Rao V, Spiro JR, Samus QM, Rosenblatt A, Steele C, Baker A, et al. Sleep disturbances in the elderly residing in assisted living: findings from the Maryland Assisted Living Study. Int J Geriatr Psychiatry. 2005; 20: 956-66.
9. Voyer P, Verreault R, Mengue PN, Morin CM. Prevalence of insomnia and its associated factors in elderly long-term care residents. Arch Gerontol Geriatr. 2006; 42: 1-20.

10. Manabe K, Matsui T, Yamaya M, et al. Sleep patterns and mortality among elderly patients in a geriatric hospital. Gerontology. 2000; 46: 318-22.

11. Kripke DF, Garfinkel L, Wingard DL, Klauber MR, Marler MR. Mortality associated with sleep duration and insomnia. Arch Gen Psychiatry 2002; 59: 13136.

12. Bloom HG, Ahmed I, Alessi CA, et al.Evidencebased recommendations for the assessment and management of sleep disorders in older persons. J Am GeriatrSoc. 2009; 57: 761-89.

13. Bombois S, Derambure P, Pasquier F, Monaca C. Sleep disorders in aging and dementia. J Nutr Health Aging. 2010; 14: 212-17.

14. Cherniack EP, Cherniack NS. Obstructive sleep apnea, metabolic syndrome, and age: will geriatricians be caught asleep on the job? Aging Clin Exp Res. 2010; 22:1-7.

15. He J, Kryger MH, Zorick FJ, Conway W, Roth T. Mortality and apnea index in obstructive sleep apnea. Experience in 385 male patients. Chest. 1988; 94: 9-14.

16. Lavie P, Lavie L, Herer P. All-cause mortality in males with sleep apnoea syndrome: declining mortality rates with age. Eur Respir J. 2005; 25: 51420.

17. Partinen M, McNicholas T. Epidemiology, morbidity and mortality of the sleep apnoea syndrome. European Respiratory Monograph. 1998; 10: 63-74.

18. Ancoli-Israel S, Kripke DF, Klauber MR, et al. Sleep disordered breathing in community-dwelling elderly. Sleep. 1991; 14: 486-95.

19. Young T, Shahar E, Nieto FJ, et al. Predictors of sleep disordered breathing in community dwelling adults: The Sleep Heart Health Study. Arch Intern Med. 2002; 162: 893-900.

20. Ancoli Israel S, Coy T. Are breathing disturbances in elderly equivalent to sleep apnea syndrome? Sleep. 1994; 17: 77-83. 
21. Ayık S, Apaydın M, Aksun S, Akhan G, Bahçeci M. Hypothyroidism in patients with obstructive sleep apnea syndrome. Dicle Med J. 2014; 41: 512-17.

22. Ogden CL, Carroll MD, Curtin LR, et al. Prevalence of overweight and obesity in the United States, 1999-2004. JAMA. 2006; 295: 1549-55.
23. Arıtürk ZA, Abakay A, Ülgen S. Obstructive sleep apnea syndrome and cardiovascular problems. Dicle Med J 2011; 38: 253-56.

24. [Obesity Diagnosis and Treatment Guide]. Obezite Tanı ve Tedavi Kılavuzu. Türkiye Endokrinoloji ve Metabolizma Derneği- 6.Baskı Miki Matbaacılık San. ve Tic. Ltd. Şti, 2018: 4-15. 